\title{
TUBERCULOSE PLEURAL EM PACIENTE SOB SITUAÇÃO DE RISCO: RELATO DE CASO
}

\section{ARTIGO ORIGINAL}

RIBEIRO, Lucas Almeida ${ }^{1}$

SOARES, Nathália Jolly Araújo ${ }^{2}$

BARBOSA, Raimundo Eri de Araújo ${ }^{3}$

ALMEIDA, Elza Mara Rezende ${ }^{4}$

RIBEIRO, Lucas Almeida. Et al. Tuberculose pleural em paciente sob situação de risco: Relato de caso. Revista Científica Multidisciplinar Núcleo do Conhecimento. Ano 05, Ed. 10, Vol. 04, pp. 121-142. Outubro de 2020. ISSN: 2448-0959, Link de acesso: https://www.nucleodoconhecimento.com.br/saude/tuberculose-pleural

\section{RESUMO}

A tuberculose (TB) é uma das enfermidades mais antigas que existem na história. $O$ primeiro relato documentado vem do século XIX, estando intimamente ligada às condições higiênico-sanitárias. O agente etiológico é o Mycobacterium tuberculosis e sua transmissão ocorre por via aérea. Atualmente, é uma patologia que enseja ainda atenção pela alta incidência entre as doenças infectocontagiosas e provoca impacto na saúde coletiva, tanto na forma tradicional (pulmonar), quanto na extrapulmonar. Os autores apresentam um caso de tuberculose pleural em paciente privado de

\footnotetext{
${ }^{1}$ Acadêmico do $11^{\circ}$ período do Curso de Medicina (UNIFAP).

${ }^{2}$ Acadêmico do $11^{\circ}$ período do Curso de Medicina (UNIFAP).

${ }^{3}$ Médico. Especialista em Ortopedista e Traumatologista. Mestre em Medicina (Clínica Cirúrgica). Professor Assistente, Curso de Medicina, UNIFAP.

${ }^{4}$ Médica. Especialista em Clínica Médica e Pneumologia. Mestre em Ensino em Ciências da Saúde. Preceptora do Internato e Residência em Clínica Médica, UNIFAP.
} 
liberdade, sob custódia judicial, diagnosticado no curso de suas internações para tratamento de fratura do fêmur e de osteomielite consequente a fratura exposta da tíbia. Além do relato, foi feita a análise deste caso baseado na literatura. A descrição do diagnóstico do paciente está intimamente atrelada a sua própria condição social. Fato este, que não deve ser exceção no contexto brasileiro. Inúmeras pessoas não aderem ao tratamento por falta de informação, perpetuando assim, a cadeia de transmissão. A metodologia do artigo trata-se de um relato de caso descritivo. Como principal resultado, pode-se afirmar que a investigação e conduta do paciente, foram alinhadas ao que se observa na literatura médica, consequentemente, chegou-se ao desfecho correto do problema. Algumas medidas simples, como a implementação de questionários para busca de SR e a busca radiológica para os casos suspeitos, levariam a uma potencial redução do número de pessoas infectadas por TB dentro dos presídios. Diversas peculiaridades podem estar atreladas a um diagnóstico, entre eles, a condição biopsicossocial do paciente. A propagação da informação ainda é um desafio muito grande a ser vencido, a educação em saúde faz-se necessária para que inúmeros indivíduos consigam entender a respeito de sua doença, sua cadeia de transmissão e sua resolução. Este artigo foi submetido e aprovado pelo comitê de ética em pesquisa da Universidade Federal do Amapá.

Palavras-chave: Tuberculose (TB), TB pleural, sintomático respiratório (SR)

\section{INTRODUÇÃO}

A tuberculose (TB) é uma das enfermidades mais antigas que existem na história. $O$ primeiro relato documentado vem do século XIX, quando dizimou centenas de pessoas, estando intimamente ligada com as condições higiênico-sanitárias. A doença continua existindo no cenário mundial, principalmente em países menos desenvolvidos, embora possa ser prevenida e curada, mas que ainda contribui para a perenização da desigualdade social (BRASIL, 2019).

O agente etiológico é o Mycobacterium tuberculosis, identificado em 1882 por Robert Koch e por isso conhecido como Bacilo de Koch (BK). Trata-se de um bacilo álcoolácido resistente (BAAR), aeróbio, com parede celular rica em micólicos e 
arabinogalactano, que the confere baixa permeabilidade, diminuição da efetividade dos antibióticos e facilita sua sobrevida nos macrófagos. A transmissão ocorre por via aérea, entre uma pessoa que possui o BK e outra que inala os aerossóis daquela por meio de tosse, espirro e/ou fala. O indivíduo com baciloscopia positiva no escarro recebe o nome de "bacilífero", sendo o principal disseminador (MENDES, 2011).

De acordo com a plataforma de dados informatizada (DATASUS) do Sistema Único de Saúde (SUS) e do Ministério da Saúde (MS), o número de casos nos últimos cinco anos, de 2014 a 2019, de Tuberculose em território nacional foi de 530.840, sendo que houve um aumento progressivo com o passar dos anos. Estes dados sustentam a importância tanto da investigação clínica, quanto do diagnóstico dessa patologia, que é uma situação de calamidade pública.

As chances de uma pessoa ser infectada pelo BK dependem de inúmeros fatores, sendo eles: a imunidade do indivíduo que inala os aerossóis, a infectividade do casofonte (bacilífero), a duração do contato com o bacilífero e o tipo de ambiente partilhado (familiares e presidiários apresentam risco aumentado em relação aos que não convivem com pessoas infectadas). Os pacientes bacilíferos são os que sustentam a cadeia de transmissão da TB, podendo infectar cerca de 15 pessoas na comunidade, em média, durante um ano. O risco de transmissão persiste enquanto houver bacilos no escarro do paciente (BRASIL, 2019).

Alguns grupos são mais vulneráveis a desenvolver TB, tais como: imunodeprimidos (portadores do HIV, de doenças - reumatológicas, por exemplo - e/ou sob tratamento imunossupressor); lactentes; idosos; moradores de rua; pessoas privadas de liberdade (PPL) e indígenas. O risco de adoecimento por TB pode ocorrer por toda a vida, sendo a TB primária (que ocorre logo depois da infecção) mais comum em crianças e imunodeprimidos e a reinfecção pode ocorrer em casos de nova exposição. Ou seja, ter contraído TB anteriormente, não confere imunidade (KRITSKI, 2018).

A TB deve ser incluída como diagnóstico diferencial em todos os casos de quadros pulmonares com sintomatologia de progressão e/ou regressão lenta como aquelas em que há febre de origem indeterminada, anorexia, tosse subaguda ou crônica e 
pneumonias de resolução lentificada. Mesmo com resultado de exame de escarro negativo, não se exclui a possibilidade da doença. Existem também outras formas de TB, denominadas de extrapulmonares. As formas extrapulmonares mais comuns são: TB pleural, empiema pleural tuberculoso, TB ganglionar periférica, TB meningoencefálica, TB pericárdica e TB óssea. Sendo a forma extrapulmonar pleural a mais frequente (BRASIL, 2019).

A TB pleural, além de ser a forma extrapulmonar mais recorrente, cursa com um quadro semelhante à pneumonia, com dor torácica do tipo pleurítica e ao longo do tempo, tende a evoluir para dispneia intensa. Deve sempre ser pensada como diferencial quando há impossibilidade de fechar um diagnóstico de TB pulmonar, caracterizado por apresentar derrame pleural, o qual consiste num acúmulo de líquido extravasado entre as pleuras visceral e parietal, com adenosina desaminase (ADA) acima de $40 \mathrm{U} / \mathrm{L}$. A ADA é uma enzima eliminada por linfócitos e monócitos quando há infecção em curso muito característica na acurácia do diagnóstico de TB. O líquido pleural decorrente da TB pleural tem características de exsudato, predomínio de linfócitos e níveis elevados de ADA, corroborando assim para fechar o diagnóstico. Epidemiologicamente, acomete homens numa proporção de $8: 1$ em relação às mulheres, na faixa etária entre 25-50 anos, sendo a principal forma extrapulmonar em pessoas não acometidas pelo HIV e habitualmente encontrados em PPL (BRASIL, 2019; SEISCENTO, 2006).

Ainda sobre a TB pleural, esta consiste na forma mais comum das extrapulmonares em pessoas não infectadas pelo HIV. Seu quadro simula pneumonia, porém com características mais exacerbadas, como dor pleurítica intensa que tende a evoluir para dispneia nos pacientes não tratados. Pode se manifestar como primoinfecção, entretanto está bastante associada com a TB pulmonar, pois podem se desenvolver os dois quadros simultaneamente. Logo, é de total importância, investigar todos os casos de longa duração que cursam com essas manifestações mencionadas (BRASIL, 2019).

Acerca da situação dos presídios brasileiros, a incidência de TB é descrita como um dado alarmante dentro da saúde pública do país. A prevalência desta entre detentos 
é até 50 vezes maior do que as médias nacionais, segundo o "Manual de recomendações de controle da tuberculose no Brasil”, 2019. Outro dado relevante engloba o fato de não apenas as PPL dentro de presídios apresentarem a doença, mas também agentes penitenciários, profissionais de saúde, visitantes e demais pessoas que trabalham na instituição possuem risco aumentado de desenvolver. As PPL geralmente são oriundas de segmentos mais afetados da população, frequentemente possuem antecedentes de TB e encarceramento, usuários de drogas ilícitas e portadores de HIV, corroborando para a prevalência da mesma (VALENÇA et al., 2015).

As pessoas privadas de liberdade (PPL) constituem um grupo de maior vulnerabilidade para contrair doenças infectocontagiosas de modo geral. O ambiente mal ventilado e superlotado favorece a disseminação destas. No caso da TB pleural nestes indivíduos, pode-se notar que muitos a desenvolvem como consequência de reativação de infecção latente e geralmente estão associadas com a TB propriamente dita, ou seja, possuem as duas formas de TB: tanto a pulmonar, como a extrapulmonar. É importante citar que a TB pleural também pode ocorrer como primoinfecção mesmo não sendo o usual (SANCHÉZ; LAROUZÉ, 2016).

Aliando TB, TB pleural e PPL, essas últimas fazem parte de grupo de maior suscetibilidade para desenvolver esses tipos de patologias, faz-se necessário uma pesquisa que englobe esses fatores, porque o Brasil ainda possui altos índices de TB pulmonar e suas formas extrapulmonares também, além de comportar uma das maiores populações carcerárias do mundo. Evidenciando que PPL infectam muito mais do que eles próprios, os trabalhadores e os visitantes conseguem contrair a doença e aumentar essa rede de transmissibilidade (BRASIL, 2019).

Por ser problema de saúde pública relevante, os autores deste artigo relatam um caso clínico de tuberculose pleural em paciente privado de liberdade, sob custódia judicial em instituição prisional na cidade de Macapá (AP), cujo diagnostico foi firmado no curso de sua internação hospitalar para tratamento de fratura recente do fêmur e de osteomielite consequente à fratura exposta tardia de tíbia. 
Este artigo procura descrever o diagnóstico do paciente que está intimamente atrelado a sua própria condição social. Fato este que não deve ser exceção no contexto brasileiro. Inúmeras pessoas não aderem ao tratamento por falta de informação, perpetuando assim, a cadeia de transmissão. É importante que o conhecimento acerca deste tema seja propagado e com isso, a educação em saúde cresça e traga bons frutos à sociedade. Esta é a contribuição do presente estudo.

O projeto desta pesquisa foi submetido à apreciação da Comissão Nacional de Ética em Pesquisa (CONEP) e do Comitê de Ética em Pesquisa (CEP) com Seres Humanos, por registro do Certificado de Apresentação para Apreciação Ética (CAAE) 39517220.0 .0000 .0003

Foram obtidos o Termo de Consentimento Livre e Esclarecido, por escrito, do participante deste estudo e o Termo de Anuência da Direção da Instituição Hospitalar conveniada à instituição superior de ensino Universidade Federal do Amapá UNIFAP e o objetivo da pesquisa fora esclarecido ao paciente de forma clara e objetiva.

O estudo observou os princípios éticos da Declaração de Helsinque (1964) e atendeu às considerações éticas dispostas na resolução 466 de 12 de dezembro de 2012 do Conselho Nacional de Saúde, que regulamenta a pesquisa envolvendo seres humanos.

\section{REFERENCIAL TEÓRICO}

A detecção da TB envolve principalmente a busca ativa pelo sintomático respiratório (SR), que consiste na pessoa que apresenta a manifestação clínica clássica, como a tosse persistente seca ou produtiva, febre vespertina, sudorese noturna e emagrecimento, por período maior ou igual a três semanas. O SR é a base da cadeia de transmissão da TB, uma vez identificado, o tratamento pode ser iniciado imediatamente, interrompendo assim, essa cadeia e reduzindo a incidência da doença (BRASIL, 2019). 
Após encontrar o caso-fonte iniciam-se as provas terapêuticas que confirmam o diagnóstico do indivíduo estima-se que para cada $100 \mathrm{SR}$ examinados, quatro sejam de fato bacilíferos. As estratégias de busca ativa permitem que as provas sejam direcionadas e usadas para interromper a propagação da TB. Dentro destas, tem-se a baciloscopia (busca do BK no escarro de forma direta), o teste rápido molecular para TB (TRM-TB) e a cultura para micobactéria, identificação e teste de sensibilidade. Preferencialmente, opta-se por fazer a baciloscopia, devido à acessibilidade do exame (WHO, 2017).

Os procedimentos recomendados na hora de realizar o teste de escarro consistem em: entregar o recipiente com tampa para o paciente, identificar o que foi entregue, o teste deve ser feito pela manhã, ao despertar, após lavar bem a boca, inspirar forte e prender a respiração para escarrar após tosse. Tem que haver três (3) eliminações de escarro, evitando que o conteúdo seja extravasado para a porção de fora do recipiente (BRASIL, 2019).

Diferentes estudos apontam uma maior sensibilidade de detecção de TB por meio de rastreio radiológico, principalmente quando são relacionados aos casos de PPL. Todavia, a disponibilidade desse tipo de equipamento, assim como de profissionais que possam realizá-lo, não é uma realidade no Brasil. Por conta da logística e do custo financeiro, os questionários acabam sendo aplicados e servindo como busca passiva no diagnóstico dessa população vulnerável (BRASIL, 2019; VALENÇA et al., 2015).

A tosse é a sintomatologia respiratória mais importante em adultos acometidos com $\mathrm{TB}$, devido à reativação do $\mathrm{BK}$, sendo caracteristicamente seca no início e podendo progredir com aspecto de escarro mucoide ou purulento. Esse sintoma, na tuberculose, pode ser classificado como tosse subaguda ou crônica, sendo a diferenciação no tempo de progressão, assim, três a oito semanas ou acima de oito semanas, respectivamente (SBPT, 2006).

No contexto de PPL, o quadro clínico pode ser subestimado. Muitos atribuem a tosse crônica ao tabagismo, hábito de vida atrelado à maioria destes indivíduos. A sudorese noturna por sua vez é compreendida como consequência ao ambiente submetido com 
um número maior de pessoas que compartilham o meio bem como a má ventilação do espaço, e também a estação climática verão. Outros sinais e sintomas, como o emagrecimento e a falta de apetite, são descritos como tristeza, depressão e demais causas emocionais. Logo, é preciso mais uma ferramenta que ajude a diagnosticar com precisão esse público (VALENÇA et al., 2016).

O derrame pleural na TB é uma forma de expressão do processo infeccioso e inflamatório de hipersensibilidade do tipo IV pela presença do bacilo. Geralmente são derrames unilaterais de pequeno a moderado volume. O diagnóstico por biópsia de fragmento pleural possui maior especificidade do que qualquer outro método utilizado, seguido pelos diagnósticos histológico, bacteriológico e cultura para TB no escarro induzido (SEISCENTO et al., 2006).

Entre os acometimentos extrapulmonares de TB devem-se destacar os casos de TB musculoesquelética, mesmo que esses sejam pouco incidentes, menos de $5 \%$ dos casos gerais em pacientes imunocompetentes. A maioria é de acometimento ósseo e o envolvimento articular está mais ligado às articulações de carga, como coluna vertebral, quadril, joelho e raramente ombros. O diagnóstico deve ser suspeitado principalmente naqueles que apresentam artrite séptica e osteomielite, situações em que há uma porta de entrada para infecção assim como um processo inflamatório instalado, propiciando ambiente adequado para reinfecção pelo BK ou disseminação hematogênica do mesmo em pacientes previamente infectados (BRASIL, 2019; OLIVEIRA et al., 2009; SEBBEN et al.; 2012).

Ainda sobre as manifestações de TB extrapulmonar, pode-se citar o tipo mais comum entre elas: a TB pleural. Esta por sua vez, corresponde à principal causa de derrame pleural no cotidiano. A pleura pode ser acometida pelo BK por via hematogênica, dissemina-se pelos folhetos pleurais num processo que é conhecido como "tuberculização", ou através de um foco pulmonar caseoso que se rompe na cavidade pleural (via direta). Nesta última via, existe grande oportunidade de encontrar o agente, tanto no líquido pleural, quanto no exame de escarro (CAPONE et al., 2006). 
A TB pleural acomete todas as faixas etárias, predominando entre adultos jovens. $\mathrm{O}$ quadro clínico é caracterizado pelos sintomas gerais que envolvem febre, astenia e emagrecimento e pela dor torácica em pontada, chamada de "pleurítica", sendo este o sintoma respiratório mais prevalente. A radiografia de tórax demonstra derrame pleural de pequeno a moderado volume, geralmente unilateral, associado a lesão parenquimatosa em $30 \%$ dos casos. Outros exames de imagem, a exemplo da tomografia computadorizada de tórax podem revelar linfonodomegalias mediastinais e/ou espessamento pleural calcificado (CAPONE et al., 2006).

A maioria dos casos de TB extrapulmonar está ligada à forma paucibacilar, ou seja, com poucos bacilos. Porém, mesmo não existindo tantos BK nestas manifestações, o diagnóstico bacteriológico deve ser pesquisado. O exame histopatológico e a cultura para micobactérias são necessários para confirmação do quadro clínico, enquanto os métodos sorológicos não estão padronizados para tal (SILVA JÚNIOR, 2012).

O diagnóstico radiológico deve ser solicitado para todo paciente com suspeita de TB, existem algumas situações em que não se torna possível devido a logística para tal, como na população carcerária. A radiografia $(R X)$ de tórax tem como objetivos além de comprovar o diagnóstico, excluir doenças pulmonares associadas, avaliar a extensão do acometimento e evolução radiológica durante o tratamento. Os resultados encontrados devem ser notificados em conjunto nas fichas de notificação compulsória. Existem outros exames de imagem que auxiliam durante a investigação, todavia só serão requisitados quando existirem dúvidas nos anteriores. Exemplos destes são: tomografia computadorizada, tomografia por emissão de pósitrons (PET), cintilografia pulmonar ventilação-perfusão e ressonância magnética (BRASIL, 2019).

Além do diagnóstico radiológico, também existe o diagnóstico histopatológico. Esse por sua vez, torna-se primordial em dois casos distintos: o primeiro quando relacionado a forma pulmonar que se apresenta radiologicamente como doença difusa e o segundo, nas formas extrapulmonares. A análise histológica acontece após a biópsia do tecido, sendo o achado confirmatório de TB o granuloma com necrose de caseificação. Outros achados através dessa biópsia são bacilos, todavia não aparecem com frequência. No caso da TB pleural, $70 \%$ dos casos apresentam o 
granuloma, ou seja, torna-se imprescindível aliar clínica, imagem e histologia (CONDE; FITERMAN; LIMA, 2011).

Após confirmação de diagnóstico de TB pulmonar e/ou extrapulmonares, deve-se iniciar o tratamento imediatamente. Este deve levar em consideração o comportamento metabólico e a localização do BK, tem por objetivos: atividade bactericida precoce, prevenção contra bacilos resistentes e ter atividade esterilizante. O esquema de tratamento é padronizado pelo Ministério da Saúde, tendo recomendações importantes para uso. Possui duas fases: intensiva (conhecida como "ataque") e manutenção. A fase intensiva tem a finalidade de diminuir rapidamente a população bacilar e com isso reduzir o risco de contágio, enquanto a fase de manutenção busca eliminar os bacilos resistentes e diminuir o risco de recidivas (ARBEX, 2010).

O esquema básico preconizado utiliza quatro drogas em uma, RHZE (Rifampicina, Isoniazida, Pirazinamina e Etambutol) ou duas em uma, RH (Rifampicina e Isoniazida). Deve ser administrado diariamente, em dose única, por via oral. A duração do tratamento é de seis meses, porém pode ser estendida até nove meses. O intervalo de tempo varia de acordo com as particularidades de cada paciente, como comorbidades associadas, grupos de maior vulnerabilidade como as PPL, pessoas vivendo com o HIV (PVHIV) e outras condições. As formas extrapulmonares, como a TB pleural, também apresentam o mesmo esquema de tratamento, assim como sua duração e devido acompanhamento (BRASIL, 2019).

\section{RELATO DE CASO}

S.M.L., homem, branco, 31 anos, PPL, natural de Macapá (AP), admitido no Hospital de Emergência Osvaldo Cruz em dezembro de 2018 com fratura complexa de fêmur distal direito, cominutiva, cursando com neuropraxia por acometimento do nervo fibular comum direito. Transferido ao Hospital de Clínicas Alberto Lima (HCAL) em fevereiro de 2019 para tratamento eletivo. Relato de fratura exposta da tíbia direita pregressa, decorrente de lesão por projetil de arma de fogo (PAF) em 2018 que, após atendimento em serviço de emergência, fora submetido a osteossíntese com haste 
intramedular bloqueada. Sem relatos de comorbidades crônicas previamente; nega alergias; não faz uso de medicamentos. Desconhece casos de doenças familiares. Fumante; uso ocasional de etílicos.

$\mathrm{Na}$ admissão ao HCAL em fevereiro de 2019, fora o paciente submetido a exames laboratorial (sangue), de imagem (radiografias e tomografia tridimensional dos segmentos de interesse em ortopedia). Realizado também eletrocardiograma (ECG), radiografias do tórax e avaliação clínica cardiológica, estes, não evidenciaram anormalidades.

Ainda em fevereiro de 2019 , notou-se pequena bolha na perna direita localizada em cicatriz de ferida operatória resultante do tratamento cirúrgico de fratura exposta da tíbia direita a que fora submetido outrora. Iniciado antibioticoterapia empírica.

Por persistência do quadro e considerando diagnóstico possível de osteomielite da tíbia direita, foi coletado material e encaminhado para exame laboratorial, cujo resultado não foi obtido. Mantido esquema de antibioticoterapia empírica.

Em vista da refratariedade à conduta medicamentosa preliminar, decidiu-se pela intervenção cirúrgica protocolar consistindo em retirada do material de osteossintese intramedular da tíbia direita e limpeza mecanocirúrgica. Procedimentos sucessivos de limpeza mecanocirúrgica foram realizados. Por ocasião das operações foi coletado material - secreção e fragmentos de tecido ósseo e encaminhados para exames de bacterioscopia, cultura e antibiograma. Reiniciou-se tratamento clínico com antibioticoterapia empírica imediatamente após a primeira operação. O esquema terapêutico foi posteriormente adequado à luz dos resultados dos exames laboratoriais de material coletado nas cirurgias realizadas, que isolou em cultura o microrganismo Staphylococcus aureus, com sensibilidade às drogas Cefepime e Vancomicina no antibiograma. Tudo, com assistência de infectologista e observada a característica da patologia - osteomielite. O paciente evoluiu satisfatoriamente e de forma resolutiva. 
No final de junho, notou-se restauração do movimento de dorsiflexão do pé direito, inicialmente comprometido por neuropraxia do nervo fibular comum.

Ainda no decorrer da internação, em 23.07.19, o paciente relatou dor no hemitórax direito (HTD), ocasião em que se encontrava consciente, orientado, eupneico, afebril e bom estado geral (BEG). Prescrito sintomáticos e solicitadas radiografias (RX) do tórax. Os exames de imagem (Figura 1) não evidenciaram alterações.

Figura 1 Radiografia de tórax em incidência anteroposterior (24/07/2019)

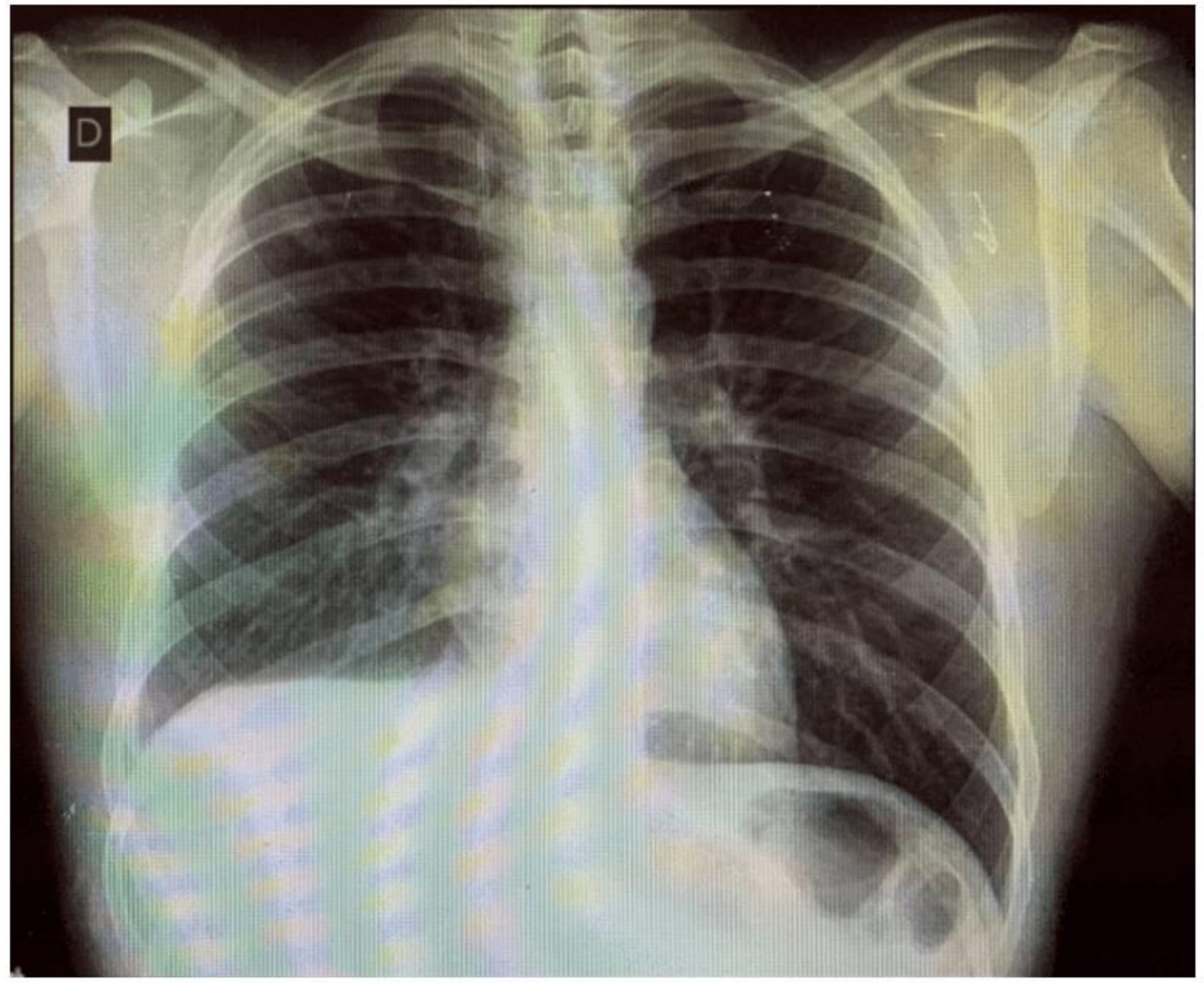

Fonte: Prontuário do paciente (2019).

O paciente evoluiu sem queixas no período, quando no final de agosto referiu tosse e febre. Em avaliação realizada pela clínica médica, foram solicitados exames diversos como RX do tórax, ultrassonografia (USG) do abdome, pesquisa de BAAR em escarro, 
sorologias para HIV, hepatite B e sífilis. Os resultados evidenciaram nas radiografias (Figura 2) do tórax volumoso derrame pleural em HTD; derrame pleural à direita na USG; pesquisa de BAAR negativo em duas amostras; sorologias negativas. Diante desses resultados, foram solicitadas avaliações das especialidades de pneumologia e de cirurgia torácica.

Figura 2 Radiografias de tórax em incidências anteroposterior (A) e perfil (B) $(27 / 08 / 2019)$

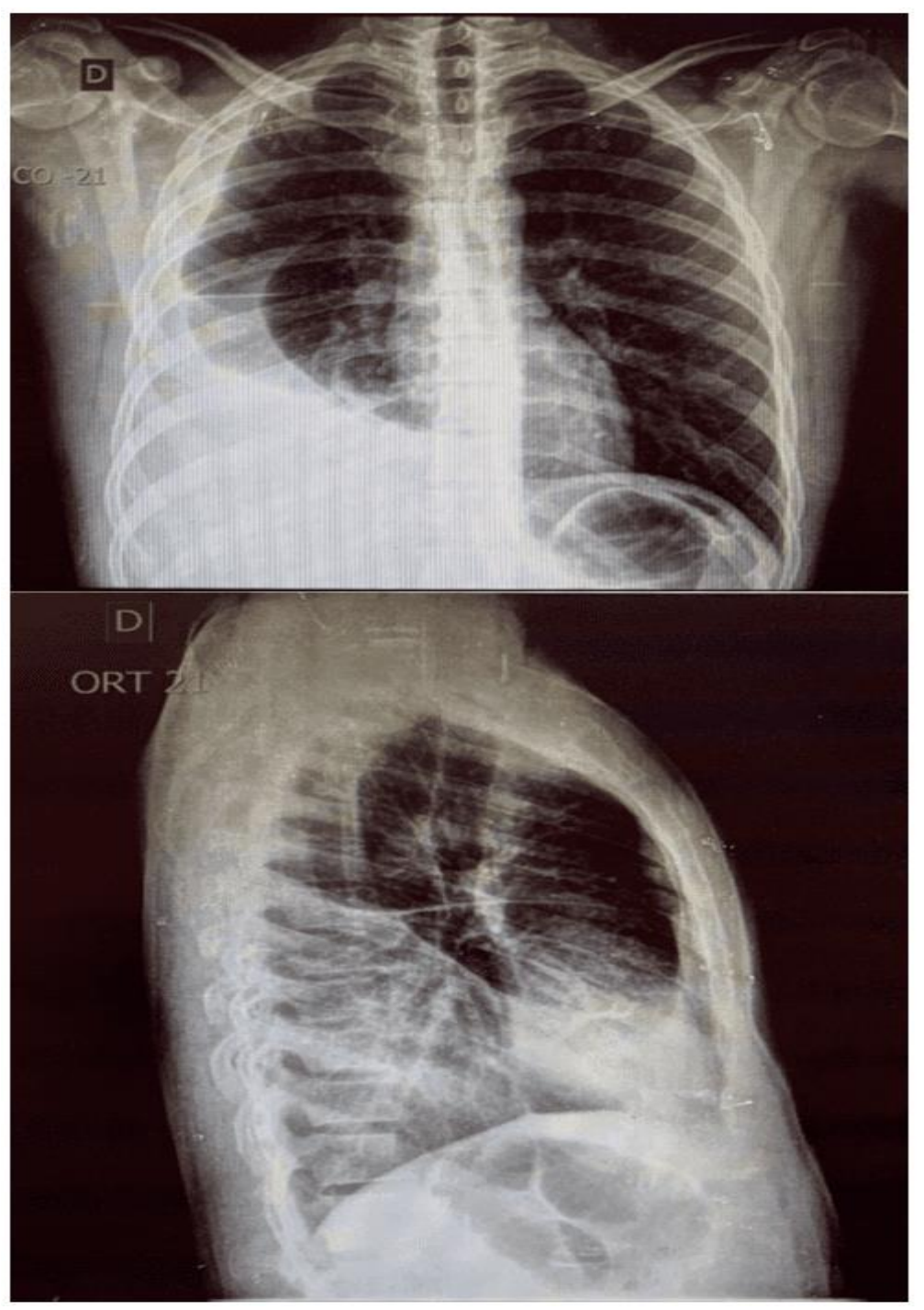

Fonte: Prontuário do paciente (2019). 
No início de setembro (03.09.19), o serviço de pneumologia interrogou possível empiema pleural nosocomial por provável disseminação hematogênica do quadro de infecção óssea pregressa - osteomielite na perna direita, como foco infeccioso primário, sendo recomendado antibioticoterapia com Linezolida. O serviço de cirurgia torácica, em discussão com os demais especialistas, indicou videopleuroscopia com biópsia, coleta de líquido pleural para análise e drenagem do derrame com instalação de dreno torácico, com fins de diagnóstico e tratamento do derrame pleural, à luz dos exames disponíveis.

Realizado pela cirurgia torácica em setembro procedimento de videopleuroscopia com drenagem do derrame pleural, biópsia da pleura ipsilateral, e instalação de dreno torácico, conforme planejamento. Iniciado subsequente esquema de antibioticoterapia (linezolida 600mg 12/12h) por dez dias. O material - fragmento e líquido pleural, foi encaminhado para exame laboratorial e análise histopatológica.

Os resultados dos exames foram disponibilizados do decorrer do mês de setembro (Tabela 1), notadamente o histopatológico de fragmento pleural apresentado foi compatível com tuberculose pleural e instituiu-se o protocolo para tratamento de TB com o esquema básico RHZE (rifampicina, isoniazida, pirazinamida e etambutol) por dois meses, em primeira fase.

A evolução clínica e exames de imagem subsequentes (controle) foram satisfatórios, obtendo o paciente alta hospitalar assintomático, com prescrição da segunda fase do esquema básico $\mathrm{RH}$ (rifampicina e isoniazida), e orientações para tratamento em nível domiciliar - eis que concedido Alvará de Soltura a PPL pela autoridade competente, e controle ambulatorial com os respectivos especialistas assistentes.

Tabela 1 Resultado de exames laboratoriais e de imagem

\begin{tabular}{|l|l|l|}
\hline DATA & EXAME & RESULTADO \\
\hline $\mathbf{1 6 / 0 5 / 2 0 1 9}$ & Cultura de tecido ósseo. & $\begin{array}{l}\text { Microrganismo isolado: Staphylococcus } \\
\text { aureus }\end{array}$ \\
\hline $\mathbf{3 0 / 0 8 / 2 0 1 9}$ & USG abdominal. & Derrame pleural à direita \\
\hline
\end{tabular}




\begin{tabular}{|c|c|c|}
\hline $\begin{array}{lr}02 & \text { e } \\
03 / 09 / 2019\end{array}$ & $\begin{array}{l}\text { Baciloscopia em escarro } \\
\text { (2 amostras). }\end{array}$ & Ausência de BAAR. \\
\hline 06/09/2019 & $\begin{array}{l}\text { Análise laboratorial de } \\
\text { líquido pleural. }\end{array}$ & $\begin{array}{l}\text { DHL: } 600 \mathrm{U} / \mathrm{L} ; \\
\text { ADA: } 73,6 \mathrm{U} / \mathrm{L} ; \\
\text { Albumina: } 2,9 \mathrm{mg} / \mathrm{dL} ; \\
\text { Glicose: } 24,2 \mathrm{mg} / \mathrm{dL} ; \\
\text { Proteínas totais: } 6,6 \mathrm{mg} / \mathrm{dL} \text {. }\end{array}$ \\
\hline $06 / 09 / 2019$ & Cultura de líquido pleural. & Não houve crescimento. \\
\hline 06/09/2019 & $\begin{array}{l}\text { Biópsia de fragmento de } \\
\text { líquido pleural } \\
\text { (micropatologia). }\end{array}$ & $\begin{array}{l}\text { Múltiplos granulomas do tipo tuberculoide } \\
\text { centrados por necrose de caseificação, } \\
\text { quadro histológico compatível com } \\
\text { tuberculose. }\end{array}$ \\
\hline
\end{tabular}

Fonte: Produzido pelos autores conforme dados do prontuário.

\section{DISCUSSÃO}

O quadro de tuberculose pleural é o mais comum entre as causas de TB extrapulmonar no Brasil, acomete preferencialmente adultos jovens numa faixa etária média dos 30 anos e corresponde a principal causa infecciosa de derrame pleural no cotidiano e em pessoas não portadoras do HIV.

Sabe-se que a população carcerária é um grupo de maior vulnerabilidade, e com isso tem maior propensão para desenvolver patologias infectocontagiosas como a TB. Um fator que contribuiria para minimizar isso seria a realização da busca ativa recomendada pelo Ministério da Saúde (MS) e que poderia ser realizada no momento do ingresso como parte da rotina admissional em até sete dias após a entrada do indivíduo na instituição prisional, juntamente com programas de educação em saúde por meio do fornecimento de informações e esclarecimento, aliado à estratégia de 
comunicação. Com a seleção previa proposta, identificação e diminuição da entrada de SR (bacilíferos), a propagação e consequente número de casos reduziria expressivamente.

Outra forma de diminuir essa cadeia de transmissão seria por intermédio da busca ativa em massa nas PPL e nos trabalhadores do local. Seja por meio de entrevista e/ou por rastreamento radiológico. Aqueles caracterizados como SR de acordo com o questionário realizado ou com alterações sugestivas em $R X$ torácico seriam submetidos a testes para diagnóstico, como a baciloscopia, ou aos demais exames que estiverem disponíveis (BRASIL, 2019).

Tratando-se do caso sob estudo e considerando o ambiente social e sanitário em que se encontrava a PPL - recluso em instituição prisional onde já cumpria apenamento por longo tempo, em compartilhamento de pequeno espaço de convivência (cela) com outras tantas pessoas, e mais recentemente, convalescendo de procedimentos cirúrgicos realizados em fevereiro e maio de 2018 para tratamento de fratura exposta de tíbia direita por PAF ocorrida em fevereiro de 2018, com assistência pós-operatória talvez insatisfatória dada a sua condição de reclusão, certamente que tudo converge para um cenário desfavorável.

Ressalte-se que o paciente sob enfoque fora novamente internado em instituições hospitalares em dezembro de 2018 e fevereiro de 2019 para tratamento de lesão traumática diversa da inicialmente descrita, cujos exames e avaliações admissionais não evidenciaram nenhuma patologia pulmonar ativa.

Nessas circunstâncias, não é possível afirmar que o quadro de TB diagnosticado no curso da última internação hospitalar tenha decorrido de infecção pelo BK na instituição prisional, se do tipo latente ou se a adquiriu no hospital. Entretanto, é possível inferir, por tudo que foi descrito, que a infecção possa ter ocorrida previamente à sua última hospitalização.

Nessa perspectiva, é extremamente comum pessoas antes infectadas desconhecerem que possuem a patologia, devido a um quadro prolongado e muitas 
vezes assintomático, principal problema da saúde pública de encontrar o caso-fonte (BRASIL, 2019; MACHADO, 2004).

Como relatado, o paciente possui histórico de dois eventos traumáticos em momentos distintos, que ensejaram internação hospitalar. O primeiro foi a fratura exposta da tíbia direita consequente a ferimento por PAF em fevereiro de 2018, ocasião em que foi submetido à operação e fixação externa, sequenciado por procedimento de conversão da fixação externa para fixação interna realizado em maio de 2018.

No transcurso da segunda internação em fevereiro 2019 em decorrência da fratura do fêmur direito, o paciente evoluiu com infecção na tíbia direita, juntamente à história pregressa de fratura exposta, quadro que se confirmou como osteomielite com o isolamento de Staphylococcus aureus em material coletado por ocasião de cirurgias para o tratamento do quadro infeccioso.

O manejo das fraturas expostas é discutido desde a antiguidade e permanece de grande interesse da ortopedia e traumatologia modernas. Uma consideração importante no emprego dos fixadores externos reside na sua conversão para um método de fixação interna (placa ou haste intramedular). Os riscos de infecção devem ser considerados (GIGLIO et al., 2015).

Por apresentar manifestações clínicas sugestivas de acometimento pulmonar na evolução, o paciente fora submetido inicialmente à baciloscopia para pesquisa de BAAR em escarro, cujas amostras se revelaram negativas, condição que não deve interromper os procedimentos para o diagnóstico de TB. Outras análises, portanto, foram realizadas e em radiografias do tórax restou evidenciado derrame pleural unilateral, impondo-se o esclarecimento da causa determinante.

Nesse contexto, é importante a diferenciação entre transudato e exsudato na análise dos derrames pleurais. Ao considerar transudato é necessário verificar na história clínica causas de insuficiência ou descompensação sistêmica como falência renal ou hepática e insuficiência cardíaca. Quanto ao exsudato, outras causas devem ser consideradas, tais como foco infeccioso, febre de origem indeterminada, malignidade, 
doenças da pleura e tuberculose. A radiografia e a análise do líquido pleural são relevantes nessa situação, pois um dos métodos para diferenciação laboratorial são os critérios de Light, que consistem na busca de proteína e DHL pleurais e séricas. De acordo com um destes critérios, o paciente em questão apresentava um derrame pleural exsudativo, pois o DHL do líquido (Tabela 1) estava maior que dois terços do limite superior da normalidade do DHL sérico (480 mg/dl). (GENOFRE, 2006).

Ademais, das formas de TB extrapulmonar, a TB pleural é a mais frequente e principal causa de derrame pleural, podendo acometer todas as faixas etárias, com predominância em adultos jovens. A radiografia do tórax demonstra derrame pleural de pequeno a moderado volume, geralmente unilateral (CAPONE et al., 2006). Portanto, há que se considerar essa hipótese diagnóstica.

No caso sob relato, o paciente clinicamente apresentou tosse e febre, e em exame radiológico foi evidenciado derrame pleural unilateral (HTD), dados que contribuíram para formulação de hipótese diagnóstica de tuberculose, confirmada com a análise histopatológica da biópsia pleural realizada, por possuir maior especificidade dentre outros métodos. (SEISCENTO et al., 2006).

Por fim, a abordagem diagnóstica do paciente foi realizada corretamente, com atenção aos procedimentos e exames realizados anteriormente, e também considerando a condição clínica do paciente. Tudo contribuiu para o adequado e tempestivo tratamento para TB, em conformidade com os protocolos do MS.

Quanto à infecção óssea da tíbia direita (osteomielite) e a infecção pulmonar (tuberculose) relatadas parece não existir correlação (etiologia e fisiopatologia diversas).

\section{CONCLUSÃO}

Algumas medidas simples, como a adoção de questionários para busca de SR e a busca radiológica para os casos suspeitos levariam a potencial redução do número de pessoas infectadas por TB dentro dos presídios. 
A investigação clínica é de suma importância para instituir o tratamento correto e tempestivo dos casos diagnosticados.

Diversas peculiaridades podem estar atreladas a um diagnóstico, entre eles, a condição biopsicossocial do paciente, portanto, aspectos culturais e sociais devem ser levados em consideração sempre numa abordagem clínica.

A difusão da informação ainda é um desafio enorme a ser vencido. A educação em saúde é relevante para que as pessoas possam entender sobre a doença, a cadeia de transmissão e a sua resolução.

\section{REFERÊNCIAS}

ASSOCIAÇÃO MÉDICA MUNDIAL. Declaração de Helsinque, 1964. Disponível em: https://www.fcm.unicamp.br/fcm/sites/default/files/declaracao_de_helsinque.pdf. Acesso em: 18 de setembro de 2020.

ARBEX, M. A. et al. Drogas antituberculose: interações medicamentosas, efeitos adversos e utilização em situações especiais - parte 1: fármacos de primeira linha. Jornal Brasileiro de Pneumologia, v. 36, n. 5, p. 641-656, 2010.

BRASIL, MINISTÉRIO DA SAÚDE. Manual de recomendações para o controle da tuberculose no Brasil. 2. ed. Atualizada. Brasília, DF, 2019.

BRASIL, MINISTÉRIO DA SAÚDE. Resolução no 466, de 12 de dezembro de 2012. Disponível em: https://bvsms.saude.gov.br/bvs/saudelegis/cns/2013/res0466_12_12_2012.html. Acesso em: 18 de setembro de 2020.

CAPONE, D. et al. Tuberculose extrapulmonar. Revista Hospital Universitário Pedro Ernesto (TíTULO NÃO-CORRENTE), [S.I.], v. 5, n. 2, dez. 2006 (Disponível em https://www.e-publicacoes.uerj.br/index.php/revistahupe/article/view/9210/7093, último acesso em 30/04/2020). 
CONDE, M.; FITERMAN, J.; LIMA, M. Tuberculose. Rio de janeiro: GEN/Guanabara Koogan, 2011.

GENOFRE, E; CHIBANTE, A. M.S; MACEDO, A.G. Derrame pleural de origem indeterminada. J. bras. pneumol., São Paulo, v. 32, supl. 4, p. S204S210, Aug. 2006.

GIGLIO, PN; CRISTANTE, AF; PÉCORA, JR. et al. Avanços no tratamento das fraturas expostas. Rev. Bras. Ortop. 2015; 50(2): 125-130.

KRITSKI, A. et al. O papel da Rede Brasileira de Pesquisas em Tuberculose nos esforços nacionais e internacionais para a eliminação da tuberculose. Jornal Brasileiro de Pneumologia, v. 44, n. 2, p. 77-81, 2018.

MACHADO, P.R.L. et al. Mecanismos de resposta imune às infecções. An. Bras. Dermatol., Rio de Janeiro, v. 79, n. 6, p. 647-662, Dez. 2004.

MENDES, E. V. As redes de atenção à saúde. [s.I.] Organização Pan-Americana da Saúde, 2011.

OLIVEIRA, M.R. et al. Tuberculose refratária disseminada com acometimento do tendão bicipital em paciente imunocompetente. Rev. bras. ortop., São Paulo, v. 44, n. 3, p. 254-259, Junho 2009.

SANCHEZ, Alexandra; LAROUZE, Bernard. Controle da tuberculose nas prisões, da pesquisa à ação: a experiência do Rio de Janeiro, Brasil. Ciência saúde coletiva, Rio de Janeiro, v. 21, n. 7, p. 2071-2080, Jul. 2016.

SBPT, SOCIEDADE BRASILEIRA DE PNEUMOLOGIA E TISIOLOGIA. II Diretrizes brasileiras no manejo da tosse crônica. J. bras. pneumol., São Paulo, v. 32, supl. 6, p. s403-s446, Nov. 2006.

SEBBEN, A. L. et al. Tuberculose de articulação coxofemoral: a propósito de um caso. Rev. Assoc. Med. Bras., São Paulo, v. 58, n. 1, p. 15-17, Fevereiro, 2012. 
SEISCENTO, M.; CONDE, M.B.; DALCOLMO, M.M.P. Tuberculose pleural. J. bras. pneumol., São Paulo, v. 32, supl. 4, p. S174-S181, Agosto, 2006.

SILVA JÚNIOR, C.T. Abordagem diagnóstica da tuberculose pleural, ganglionar, renal e de sistema nervoso central. Pulmão RJ. 2012; 21(1):32-35.

VALENCA, M. S. et al. O processo de detecção e tratamento de casos de tuberculose em um presídio. Ciência saúde coletiva, Rio de Janeiro, v. 21, n. 7, p. 2111-2122, Julho, 2016.

VALENCA, M. S. et al. Tuberculose em presídios brasileiros: uma revisão integrativa da literatura. Ciência saúde coletiva, Rio de Janeiro, v. 21, n. 7, p. 21472160, Julho, 2016.

WHO, WORLD HEALTH ORGANIZATION. Global tuberculosis report 2017. [s.I.] Geneva: WHO, 2017.

Enviado: Setembro, 2020.

Aprovado: Outubro, 2020. 